Volume 3, Number 4, Iranian Journal of Educational Sociology $\mid 170$

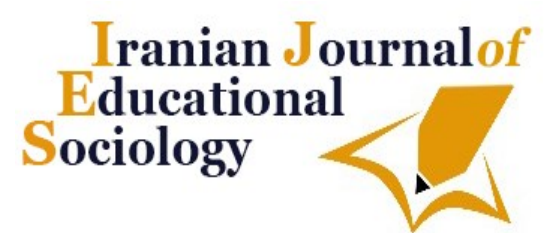

Iranian Journal of Educational Sociology

(Interdisciplinary Journal of Education)

Available online at: $\underline{\text { http://www.iase-idje.ir/ }}$

Volume 3, Number 4, March 2020

\title{
Identify the Effective Factors on Justice-Oriented in Attracting, Retaining and Promoting Human Resources and Provide an Appropriate Pattern
}

\author{
Mohammad Kazemzadeh Hochghan ${ }^{1}$, Reza NajafBeigi ${ }^{2 *}$, Naser Mirsepasi ${ }^{2}$, Karamollah Daneshfard ${ }^{2}$ \\ 1. PhD Student of Human Resources, Department of Public Administration, Qeshm Branch, Islamic Azad University, Qeshm, Iran. \\ 2. Professor, Department of Public Administration, Science and Research Branch, Islamic Azad University, Qeshm, Iran.
}

\section{Article history:}

Received date: $2020 / 08 / 22$

Review date: $2020 / 10 / 25$

Accepted date: 2020/10/31

\section{Keywords:}

Justice-Oriented, Attracting, Retaining, Promoting, Human

Resources

\begin{abstract}
Purpose: The aim of this study was to identify the factors affecting justiceoriented in attracting, retaining and promoting human resources and provide a favorable model.

Methodology: This study was applied in terms of purpose and qualitative in terms of implementation. The study population was all articles related to the role of justice-oriented in attracting, retaining and promoting human resources in the scientific databases of Magiran, Scopus from 1991-1992 (227 articles) and managers and human resources experts in government organizations in Tehran in 2018-19. The research sample consisted of 40 articles and 15 experts who were selected according to the principle of theoretical saturation and purposive sampling. Data were collected by filing methods and interviews with specialists and their psychometric indices. Content analysis method was used to analyze the data.

Findings: The results showed that the effective factors in justice-oriented in all three processes of recruitment, retention and promotion of human resources included both external and internal factors. For the external factor in all three processes of recruitment, retention and promotion of manpower, four dimensions including cultural $(5$ common indicators for all three processes of recruitment, retention and promotion of human resources), economic (5 common indicators for all three processes), social (4 indicators Common to all three processes) and political (1 common indicator for all three processes) and for the internal factor three dimensions including management of ethics, values and culture (6 common indicators for all three processes), individual (indicators were different and 4 indicators to attract , 3 indicators for maintenance and 6 indicators for upgrade) and internal indicators (indicators were different and 5 indicators for absorption, 5 indicators for maintenance and 5 indicators for upgrade) were identified. In total, 2 factors, 7 dimensions and 48 indicators were identified and based on that, an appropriate model of factors affecting justice-oriented in attracting, retaining and promoting human resources was designed.

Conclusion: According to the research findings, the effective factors in justice-oriented in all three processes of recruitment, retention and promotion of human resources included both external and internal factors.
\end{abstract}

Please cite this article as: Hochghan M K, NajafBeigi R, Mirsepasi N, Daneshfard K. (2020). Identify the Effective Factors on Justice-Oriented in Attracting, Retaining and Promoting Human Resources and Provide an Appropriate Pattern. Iranian Journal of Educational Sociology. 3(4): 170-179.

\footnotetext{
* Corresponding author: najafbeigi@gmail.com
} 


\section{Introduction}

The general policies of the administrative system are in fact macro-administrative policies communicated by the Supreme Leader and, as a model and guide for the activities of the three branches, guide the administrative system. Therefore, by improving the capabilities of the administrative system, a suitable tool can be provided to implement the provisions of Vision 1404, and the second paragraph of the general policies of the administrative system of this vision addresses the issue of justice in attracting, retaining and promoting human resources (Rahnavard, 2013). The third paragraph of Vision 1404 and Article 28 of the Constitution also improve the criteria and update the methods of selecting human resources to attract capable, committed and competent human resources. Also, in the Civil Service Management Law, Chapter 7 deals with the issue of employment, Chapters 8 and 9 deal with the issue of job appointment and promotion, and Empowerment of employees, and Chapter 10 deals with salaries and benefits related to employee retention (Ghamami \& Azizi, 2014). In addition, the success of any organization depends on the appropriate allocation and employment of appropriate human resources, and this will be possible if organizations can use the skills, abilities and individual and collective characteristics of their employees in line with the goals of the organization (Alves \& Mariano, 2018). The most important asset of any organization is its human resources and the fate of the organization is tied to the fate of human resources. In recent years, attention to human resources in organizations has taken up a large part of the time and capital of leading organizations, and the success or failure of the organization depends on how to attract and retain human resources (Newman, \& et al, 2020).

In Iran, human resource management in organizations is more a function of individual tastes and factors such as kinship and acquaintance, advice of influential officials, high level of organizational affiliation and personal relations (Ahmadi \& et al, 2017) instead of law or justice. Justice means respecting rights and balance, and organizational justice is achieved when employees feel and understand that organizational rules, procedures, and policies are fair. This means that social and human relations should be balanced in a balanced way and every institution and organization and every relationship should be in its real position and the position of each phenomenon should always be determined in relation to the purpose of the system and set and based on principles, characteristics and Features governing the system (Bouazzaoui \& et al, 2020). Thus, justice is only the origin of human social arrangements and interactions, and as the only absolute social value can form the basis of social relations (Wolfe \& et al, 2018). The main issue of justice is the basic structure of society and the mechanism by which social institutions determine the basic rights and duties in distribution and how the benefits of social cooperation are distributed. Justice, then, is the elimination of unreasonable privileges and the creation of a real balance between the conflicting demands of human beings, which is envisaged in the structure of an organization, and justice is achieved when the correct distribution of benefits and responsibilities in social cooperation is achieved (Akram \& et al, 2020). In manpower management, there are three important processes of manpower recruitment, retention and promotion. If justice-oriented is considered in the true sense of the word in any of these processes, many individual and organizational interests will be created (Radzi \& et al, 2009). In the approaches of training and evaluation, job experience, personal relationships and the process of human resource development and promotion, the justice-centered factor must be considered so that the three processes of recruiting, retaining and promoting employees are systematic and principled. In the process of recruiting justice-oriented manpower, attention should be paid to the personal, professional and cognitive competencies of the candidates, determining the exact criteria and criteria for selecting individuals, holding exams, creating equal opportunities for all, legalism and building trust. Also, in this process, all the factors of the system, ie the needs of the organization, methods of providing human resources, methods of selecting and hiring volunteers, appointment and selection to establish employment justice must be considered (Ahmadi \& et al, 2017). Factors influencing employee retention include cultural, organizational, and governmental factors. Other factors affect the recruitment, retention and promotion of human resources, the most important of 
which are the content and nature of the job, management and leadership, clear goals and expectations, the atmosphere of cooperation and group cohesion, assignment of jobs and positions based on merit, effective evaluation system Job security, working environment conditions, nature of work and communication, education and development, social support, managers' motivational behaviors, employee motivation, distributive justice, procedure and interaction, job independence, appropriate rights and demographic factors (education, age, gender, length Service, etc.) noted (Tavakkolinejad \& et al, 2016).

There have been few and sparse studies on the processes of attracting, retaining and promoting human resources in organizations, but no research has been found that examines all three processes. For example, the results of Teimouri et al. (2018) showed that the factors affecting the recruitment of manpower include eight main dimensions including environmental factors affecting the determination of strategies, trustees of recruitment and supply of manpower, human resource planning based on job competencies, determining competency criteria, Matching competencies with jobs, manpower recruitment measures, manpower supply measures, and internal and external consequences. The results of Rezaeian, et al.'s (2018) research include the criteria for attracting talented human resources, including attracting criteria and resources for recruitment with strategic goals, being committed and trustworthy, idea-oriented and deconstructive, having the minimum individual characteristics required by the organization, attracting talent and justiceoriented. Having specific personality traits of the organization and their maintenance characteristics include experiential succession, creating a field for identifying and developing talents, creating a capable system of performance appraisal, creating a clear distinction between talented and ordinary people, creating equal opportunities for growth, creating financial dependence, development and upbringing They introduced talents, creating a learning and ideological environment and creating a sense of fairness and justice. Ahmadi, et al. (2017) in a study concluded that the factors affecting the recruitment of justice-based human resources included responsibility, commitment, motivation, organizational rules, organizational culture and organizational goals. In another study, Tavakkolinejad, et al. (2016) reported that the effective factors in retaining employees of government organizations include organizational factors (nature of job, job promotion, payment system, leadership style and social support), cultural factors (power distance, individualism, fear of Change in the future and avoid ambiguity in decision-making) and government factors (public interest, decision-making realm and job effects). Also, Ranjbar \& Shafizadeh (2016) consider the factors affecting the survival of employees as job security, non-discrimination between employees and fairness, appropriate salaries and benefits, respect for employees, insurance services, various financial rewards, job promotion, supervisor and Management style, organizational housing, independence and authority for employees, good colleagues, performance appraisal, health and safety at work, physical condition of the workplace, participation in work and decision making, non-financial incentives, in-service training, consumption cooperatives and nutrition services The staff introduced. In another study, Mirkamali, et al. (2015) reported that the criteria for attracting and retaining human resources included organizational, occupational, personal competencies, doctrinal and religious issues, and special privileges. In addition, Wadhwa \& Madan (2017) in their research concluded that the most important barriers to employee retention are better job prospects, higher pay, flexible working hours, and better work environment and so on. In another study, Kyndt, et al. (2009) reported that personal and organizational perspectives on employee retention included organizational commitment, motivation, innovation, continuous employee development, job security, leadership skills, employee appreciation, and service delivery.

There are many processes involved in the success and effectiveness of the organization, one of which is the process of attracting the right employees, and these employees can create a competitive advantage for the organization. Other important and effective processes include staff retention and promotion. Given today's changing world, the organization can be in a favorable position compared to other organizations if it is successful in the processes of attracting, retaining and promoting its employees. One of the issues that can 
be effective in the realization of the above processes is justice-oriented. Therefore, it is necessary to examine the factors affecting justice in attracting, retaining and promoting employees. Although little and scattered research has been done on the processes of recruitment, retention and promotion of human resources in organizations, but a study that has examined all three processes of recruitment, retention and promotion of human resources has not been found and another important point is that research on factors Effective justice has not been done in three processes. As a result, the present study was conducted with the aim of identifying the factors affecting justice-oriented in attracting, retaining and promoting human resources and providing a desirable model.

\section{Methodology}

This study was applied in terms of purpose and qualitative in terms of implementation method. The research population was all articles related to the role of justice-oriented in attracting, retaining and promoting human resources in the scientific databases of 2020-1991 (227 articles) and human resource managers and experts in government organizations in Tehran in 2018-19. The research sample consisted of 40 articles and 15 experts who were selected according to the principle of theoretical saturation and purposive sampling.

According to the purpose of the research, the researcher first studied books and documents related to justice-oriented in attracting, retaining and promoting human resources, and then 227 articles were identified and reviewed among the articles in reputable databases, including Scopus. Based on this study, factors, dimensions and indicators were identified as effective factors in justice-oriented in attracting, retaining and promoting human resources. This process took place systematically in two stages. The first phase involved a vocabulary search in the titles of the articles as the initial analysis unit, and terms such as recruiting, hiring, retaining, retaining, developing and promoting justice-based staff were examined, based on which 227 articles were identified. The second step consisted of reviewing the titles, abstracts and keywords of the identified articles in order to extract articles that had specialized in the relevant field. The purpose of this stage was to remove articles unrelated to the purpose of the research. At the end of this stage, 40 articles were selected. Then, 40 articles were reviewed by content analysis method. For this purpose, an attempt was made to carefully examine and study the articles, to extract the qualitative concepts contained in them. After identifying the factors affecting justice-oriented, the experts were interviewed according to the following questions and the opinions of experts (managers and human resources experts) about them were reviewed and after applying their opinions several times, they were approved by the experts.

Table1. Main and sub-questions of the interview

\begin{tabular}{cl}
\hline $\begin{array}{c}\text { General } \\
\text { question }\end{array}$ & $\begin{array}{l}\text { What are the factors affecting justice in attracting, retaining and promoting human resources and what is the } \\
\text { appropriate model? }\end{array}$ \\
\hline \multirow{2}{*}{$\begin{array}{l}\text { Minor } \\
\text { questions }\end{array}$} & $\begin{array}{l}\text { 2. What are the factors affecting the central justice in attracting human resources and its appropriate model? } \\
\text { model? }\end{array}$ \\
\cline { 2 - 3 } & $\begin{array}{l}\text { 3. What are the factors affecting justice in the promotion of human resources and what is the appropriate } \\
\text { model? }\end{array}$
\end{tabular}

Data were collected by filing methods and interviews with specialists and their psychometric indices. Content analysis method was used to analyze the data. 


\section{Findings}

Factors influencing justice-oriented in all three processes of recruitment, retention and promotion of human resources included both external and internal factors. Table 2 reports the results of content analysis to identify the factors, dimensions and indicators of justice-oriented in the process of manpower recruitment.

Table2. Factors, dimensions and indicators of central justice in the process of manpower recruitment

\begin{tabular}{|c|c|c|}
\hline Factors & Dimensions & Indicators \\
\hline \multirow{4}{*}{$\begin{array}{l}\text { External } \\
\text { factor }\end{array}$} & Cultural & $\begin{array}{l}\text { 1. Government support, 2. Lack of various information, financial rents, etc., } 3 . \\
\text { Acceptance of religious teachings, } 4 \text {. Groups of power and influence, and } 5 \text {. The mental } \\
\text { attitude of society }\end{array}$ \\
\hline & Economic & $\begin{array}{l}\text { 1. Unemployment rate, 2. Economic development index, 3. Poverty index, 4. Proportion } \\
\text { of income growth and inflation, and } 5 \text {. Economic growth }\end{array}$ \\
\hline & social & $\begin{array}{l}\text { 1. Age, 2. Employment rate, 3. Social participation rate, 4. Labor-related laws and } \\
\text { regulations }\end{array}$ \\
\hline & Political & 1. The level of political relations of the country with other countries \\
\hline \multirow{3}{*}{$\begin{array}{l}\text { Internal } \\
\text { factor }\end{array}$} & $\begin{array}{l}\text { Managing ethics, } \\
\text { values and culture }\end{array}$ & $\begin{array}{l}\text { 1. Observance of ethics, 2. Existence of groups of power and influence, 3. Tendency to } \\
\text { flatter and flatter, 4. Overcoming emotions at work, 5. Partying and 6. Extravagance of } \\
\text { people }\end{array}$ \\
\hline & Individual & $\begin{array}{l}\text { 1. Competence, 2. Personality type, } 3 \text {. Individual self-efficacy and 4. Professional ethics } \\
\text { and responsibility }\end{array}$ \\
\hline & Internal organization & $\begin{array}{l}\text { 1. Strong evaluation team during recruitment, 2. Description of fulfillment of job duties, } \\
\text { 3. Location, 4. Organizational rules and regulations, and 5. Clarity of vision and mission } \\
\text { of the organization }\end{array}$ \\
\hline
\end{tabular}

According to the results of Table 2, in the process of manpower recruitment, the external factor has four dimensions of cultural ( 5 indicators), economic ( 5 indicators), social (4 indicators) and political (1 index) and the internal factor has three dimensions of ethics, values and culture management. (6 indicators), individual (4 indicators) and internal organization ( 5 indicators), Table 3 reports the results of content analysis to identify the factors, dimensions and indicators of justice-oriented in the process of retaining manpower.

Table3. Factors, dimensions and indicators of justice in the process of retaining manpower

\begin{tabular}{|c|c|c|}
\hline Factors & Dimensions & Indicators \\
\hline \multirow{4}{*}{$\begin{array}{l}\text { External } \\
\text { factor }\end{array}$} & Cultural & $\begin{array}{l}\text { 1. Government support, 2. Lack of various information, financial rents, etc., } 3 . \\
\text { Acceptance of religious teachings, } 4 \text {. Groups of power and influence, and } 5 \text {. The mental } \\
\text { attitude of society }\end{array}$ \\
\hline & Economic & $\begin{array}{l}\text { 1. Unemployment rate, 2. Economic development index, 3. Poverty index, 4. Proportion } \\
\text { of income growth and inflation, and } 5 \text {. Economic growth }\end{array}$ \\
\hline & social & $\begin{array}{l}\text { 1. Age, 2. Employment rate, 3. Social participation rate, 4. Labor-related laws and } \\
\text { regulations }\end{array}$ \\
\hline & Political & 1. The level of political relations of the country with other countries \\
\hline \multirow{3}{*}{$\begin{array}{l}\text { Internal } \\
\text { factor }\end{array}$} & $\begin{array}{l}\text { Managing ethics, } \\
\text { values and culture }\end{array}$ & $\begin{array}{l}\text { 1. Observance of ethics, 2. Existence of groups of power and influence, } 3 \text {. Tendency to } \\
\text { flatter and flatter, 4. Overcoming emotions at work, 5. Partying and 6. Extravagance of } \\
\text { people }\end{array}$ \\
\hline & Individual & $\begin{array}{l}\text { 1. Personal perspective, 2. Professional competencies and 3. Individual commitment to } \\
\text { the organization }\end{array}$ \\
\hline & Internal organization & $\begin{array}{l}\text { 1. Evaluation and reward system, 2. Payroll system, 3. Organization brand, 4. Spiritual } \\
\text { support and 5. Participation opportunity }\end{array}$ \\
\hline
\end{tabular}

According to the results of Table 3, in the process of manpower recruitment, the external factor has four dimensions of cultural ( 5 indicators), economic ( 5 indicators), social (4 indicators) and political (1 index) and the internal factor has three dimensions of ethics, values and culture management. (6 
indicators), individual (3 indicators) and internal organization (5 indicators), Table 4 reports the results of content analysis to identify the factors, dimensions and indicators of justice in the process of human resource development.

Table4. Factors, dimensions and indicators of justice in the process of human resource development

\begin{tabular}{|c|c|c|}
\hline Factors & Dimensions & Indicators \\
\hline \multirow{4}{*}{$\begin{array}{l}\text { External } \\
\text { factor }\end{array}$} & Cultural & $\begin{array}{l}\text { 1. Government support, 2. Lack of various information, financial rents, etc., } 3 . \\
\text { Acceptance of religious teachings, } 4 \text {. Groups of power and influence, and } 5 \text {. The mental } \\
\text { attitude of society }\end{array}$ \\
\hline & Economic & $\begin{array}{l}\text { 1. Unemployment rate, 2. Economic development index, 3. Poverty index, 4. Proportion } \\
\text { of income growth and inflation, and } 5 . \text { Economic growth }\end{array}$ \\
\hline & social & $\begin{array}{l}\text { 1. Age, 2. Employment rate, 3. Social participation rate, 4. Labor-related laws and } \\
\text { regulations }\end{array}$ \\
\hline & Political & 1. The level of political relations of the country with other countries \\
\hline \multirow{3}{*}{$\begin{array}{l}\text { Internal } \\
\text { factor }\end{array}$} & $\begin{array}{l}\text { Managing ethics, } \\
\text { values and culture }\end{array}$ & $\begin{array}{l}\text { 1. Observance of ethics, 2. Existence of groups of power and influence, 3. Tendency to } \\
\text { flatter and flatter, 4. Overcoming emotions at work, 5. Partying and 6. Extravagance of } \\
\text { people }\end{array}$ \\
\hline & Individual & $\begin{array}{l}\text { 1. The level of education, } 2 \text {. The use of creativity and individual talents, } 3 \text {. The } \\
\text { relationship between the field of study and the job, } 4 \text {. The level of commitment to the } \\
\text { ideals of the organization, } 5 \text {. The level of spirit and feeling of participation in teamwork } \\
\text { and 6. Satisfaction with the type of work }\end{array}$ \\
\hline & Internal organization & $\begin{array}{l}\text { 1. Service history, 2. Competence in holding organizational position, 3. Having authority } \\
\text { in work, 4. Participation in decision-making and } 5 \text {. In-service training }\end{array}$ \\
\hline
\end{tabular}

According to the results of Table 4, in the process of manpower recruitment, the external factor has four dimensions of cultural ( 5 indicators), economic ( 5 indicators), social (4 indicators) and political (1 index) and the internal factor has three dimensions of ethics, values and culture management. (6 indicators), individual (6 indicators) and internal organization (5 indicators), According to the results of Tables 2, 3 and 4 , the factors affecting justice-oriented in all three processes of recruitment, retention and promotion of manpower included both external and internal factors. For the external factor in all three processes of recruitment, retention and promotion of manpower, four dimensions including cultural $(5$ common indicators for all three processes of recruitment, retention and promotion of human resources), economic (5 common indicators for all three processes), social (4 indicators Common to all three processes) and political (1 common indicator for all three processes) and for the internal factor three dimensions including management of ethics, values and culture (6 common indicators for all three processes), individual (indicators were different and 4 indicators to attract, 3 indicators for maintenance and 6 indicators for upgrade) and internal indicators (indicators were different and 5 indicators for absorption, 5 indicators for maintenance and 5 indicators for upgrade) were identified. In total, 2 factors, 7 dimensions and 48 indicators have been identified and based on that, the appropriate model of factors affecting justice-oriented in the processes of recruitment, retention and promotion of human resources has been designed in Figure 1. 


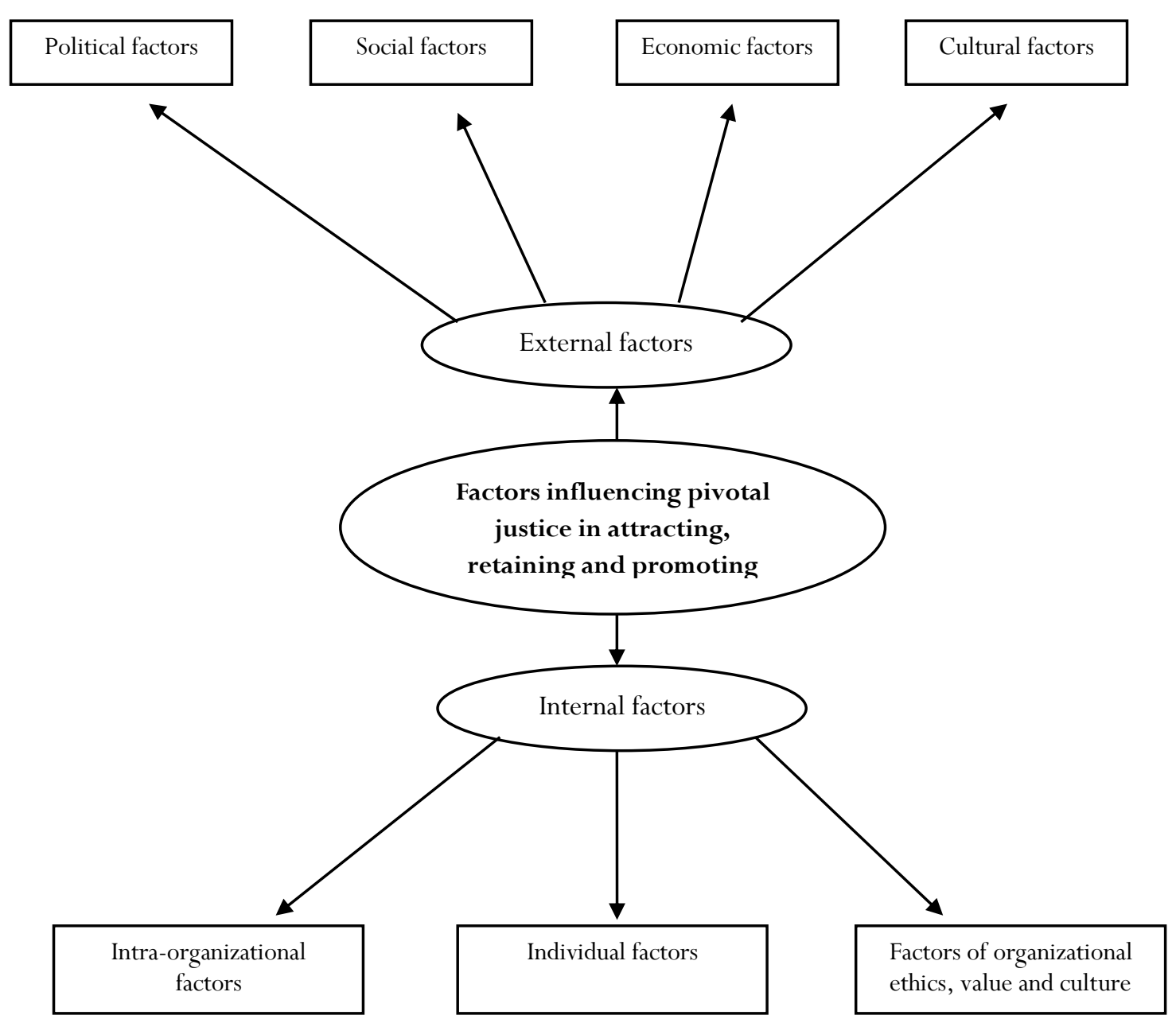

Figure2. Optimal justice-oriented model in the processes of attracting, retaining and promoting human resources

\section{Discussion}

Considering the role and importance of justice-oriented on organizational performance and effectiveness and little research background on identifying the factors affecting the processes of recruitment, retention and promotion of human resources based on justice-oriented, the present study aims to identify the factors affecting justice-oriented in attracting, retaining and promoting human resources, And provided a favorable pattern. The findings of the present study showed that the effective factors in justice-oriented in all three processes of attracting; retaining and promoting human resources included both external and internal factors. For the external factor in all three processes of attracting, retaining and promoting human resources, four dimensions including cultural, economic, social and political, and for the internal factor in all three processes of attracting, retaining and promoting human resources, three dimensions include managing ethics, values and culture. And internal organization was identified. In total, 2 factors, 7 dimensions and 48 indicators were identified and based on that, an appropriate model of factors affecting justice-oriented in attracting, retaining and promoting human resources was designed.

These findings are in line with the findings of Teimouri et al. (2018), Rezaeian et al. (2017), Ahmadi et al. (2017), Tavakkolinejad et al. (2016), Ranjbar \& Shafizadeh (2016), Mirkamali et al. (2015), Wadhwa. \& Madan (2017) and Kyndt et al. (2009) were consistent. For example, Teimouri et al. (2018) in a study 
concluded that the factors affecting the recruitment of manpower include eight main dimensions including environmental factors affecting the determination of strategies, recruiters and recruitment of manpower, human resource planning based on job competencies, criteria Competence was the matching of competencies with jobs, manpower recruitment measures, manpower supply measures, and internal and external consequences. In another study, Tavakkolinejad et al. (2016) reported that the effective factors in retaining employees of government organizations include organizational factors (nature of job, job promotion, payment system, leadership style and social support), cultural factors (power distance, individualism, fear of Change in the future and avoid ambiguity in decision-making) and government factors (public interest, decision-making realm and job effects). In addition, Wadhwa \& Madan (2017) in their research concluded that the most important barriers to employee retention are better job prospects, higher pay, flexible working hours, and better work environment and so on. In another study, Kyndt et al. (2009) reported that personal and organizational perspectives on employee retention included organizational commitment, motivation, innovation, continuous employee development, job security, leadership skills, employee appreciation, and service delivery.

The dimensions affecting justice-oriented in all three processes of recruiting, retaining and promoting the same manpower are the same and the indicators in all three processes were relatively common. Therefore, in order to improve the performance and effectiveness of the organization, justice-oriented should be considered in all organizational processes, including recruitment, employment, retention or promotion of human resources, and employees should believe in justice throughout the organization. In such an organization, everything happens according to the rules and regulations, and the goals of the organization and how to receive rewards and career advancement are clear to all employees. In all three processes of recruiting, retaining and promoting human resources, indicators such as government support for the organization, lack of rents, acceptance of religious teachings, economic growth and development of employees and the organization, employee participation in decision-making, compliance with organizational rules and regulations and political relations with other countries. External factor and observance of ethics, non-partisanship and extravagance, control of emotions at work, creativity and individual talents, organizational commitment, participation in work and satisfaction with it, meritocracy, willpower and participation in organizational decisions play an effective role in internal factor In the perception of justice, it will be centered on employees and other members of society towards the organization.

The organization as an institution that is responsible for organizing human resources and facilities and resources to advance organizational goals cannot be achieved without human resources. Therefore, manpower is considered as an important asset in the organization and organizations plan and spend to have an efficient and useful workforce, and that is why maintaining and promoting manpower is very important for organizations. Because leaving the service of manpower, in addition to disrupting the work, causes a waste of investments that have been spent to attract, retain and improve that workforce in the organization. Therefore, in addition to retaining effective employees, organizations plan to retain and improve them, and in order to eliminate the causes of leaving the service and create conditions and facilities for employees to continue their service, it is necessary to plan and factors, dimensions and justice-oriented indicators, Retention and promotion of human resources can serve as a relatively comprehensive model to help officials and senior managers of organizations.

The results of the present study indicate the role of cultural, economic, social and political dimensions in the external dimension and the dimensions of ethics management, values and culture, individual and internal organization in the internal dimension as factors affecting justice in all three processes of attracting, retaining and promoting human resources. One of the limitations of the present study is the small number of interviewees, few studies on the factors affecting justice-oriented, especially in the process of human resource development and the limited number of interviewees to the city of Tehran. Therefore, it is recommended to conduct interviews with more people and specialists and experts from other cities. 
Another suggestion is to study the factors affecting the processes of attracting, retaining and promoting human resources by eliminating justice-oriented. Undoubtedly, by using various models and patterns regarding the recruitment, retention and promotion of human resources and their integration, an effective step can be taken in this field. Considering the factors, dimensions and indicators affecting justice-oriented in attracting, retaining and promoting human resources, it is necessary to design programs to create and promote the recruitment, retention and promotion of human resources. Therefore, professionals and managers of organizations can provide the basis for improving the recruitment, retention and promotion of human resources by promoting factors, dimensions and indicators based on justice. Another practical suggestion is that managers and officials of organizations should consider the indicators of manpower recruitment at the time of employment and to maintain and improve their human resources, especially efficient and practical forces that have the ability to create a competitive advantage, maintain and improve their indicators to the extent it is possible to run. 


\section{References}

Ahmadi P, Mousakhani M, Memarzadeh Gh, Alam Tabriz A. (2017). Designing a model for attracting human resources based on justice for Iranian government agencies. Urban Management. 47: 49-60.

Akram T, Lei S, Haider MJ, Hussain ST. (2020). The impact of organizational justice on employee innovative work behavior: Mediating role of knowledge sharing. Journal of Innovation \& Knowledge. 5(2): 117-129.

Alves MWFM, Mariano EB. (2018). Climate justice and human development: A systematic literature review. Journal of Cleaner Production. 202: 360-375.

Bouazzaoui M, Wu H, Roehrich JK, et all. (2020). Justice in inter-organizational relationships: A literature review and future research agenda. Industrial Marketing Management. 87: 128-137.

Ghamami SMM, Azizi H. (2014). Principles and principles of employment justice in the Islamic legal system. Administrative Law. 1(4): 113-134.

Kyndt E, Dochy F, Michielsen M, Moeyyaert B. (2009). Employee retention: Organisational and personal perspectives. Vocations and Learning. 2: 195-215.

Mirkamali SM, Hajkhozeymh M, Ebrahimi S. (2015). Criteria to identify attract and retain human resources and provide appropriate solutions (Case study: Staff of Tehran University Campus Faculties). Journal of Development Evolution Management. 22: 9-18.

Newman DT, Fast NJ, Harmon DJ. (2020). When eliminating bias isn't fair: Algorithmic reductionism and procedural justice in human resource decisions. Organizational Behavior and Human Decision Processes. 160:149-167.

Radzi SM, Zuraini S, Zahari MSM, Othman Z. (2009). An empirical assessment of hotel departmental managers turnover intentions: The impact of organizational justice. International Journal of Business and Management. 4(8): 173-183.

Rahnavard F. (2013). Administration system architecture in the light of general public policies. Journal of Development Evolution Management. 10: 15-22.

Ranjbar H, Shafizadeh H. (2016). Identify and prioritize the factors affecting the survival and sustainability of municipal employees in district 13 in Tehran. Urban Management Studies. 7(24): 64-77.

Rezaeian A, Kazem Sadaei M, Gharache M, HajiKarimi A. (2018). Identifying indicators of attracting, maintenance and retaining of talented human resources in banking industry. Public Administration Perspective. 9(35): 15-38.

Tavakkolinejad H, Jazani N, Memarzadeh Tehran Gh, Afshar Kazemi MA. (2016). The model retention of employees of public organizations. International Journal of Urban and Rural Management. 15(43): 291-304. 